\title{
Importance of Resource Mobilization (RM) for Development of Herbal Medicine: A Comprehensive Approach
}

\section{Mohammad NI}

Department of Unani Medicine, Hamdard University, Bangladesh

"Corresponding author: Mohammad NI, Assistant Professor, Department of Unani Medicine, Hamdard University, Gazaria, Bangladesh, Tel: 008801732780912; E-mail: dr_sayemnazrul@yahoo.com

Received date: May 2, 2017; Accepted date: May 15, 2017; Published date: May 20, 2017

Copyright: (c) 2017 Mohammad NI. This is an open-access article distributed under the terms of the Creative Commons Attribution License, which permits unrestricted use, distribution and reproduction in any medium, provided the original author and source are credited.

\begin{abstract}
Historical evidence showed that from ancient to till now herbal medicine has been empirically used for treatment of different health ailments. Scientist, herbalist, physicians and experts from diversified fields are contributing to develop herbal medicine in the world. All of the researchers are morally coincided that maximum utilization and mobilization of resources (men, materials and money) are prime demand to propagate herbal medicine in the world. Some of the scientist also claimed that lack of expert in the field of herbal medicine is prime drawback to develop herbal medicine. It is true but expert in the field of herbal medicine are until struggling for positional crisis. Without changing the propaganda, it is not possible to achieve the desire goal of herbal medicine. So, it is time demanded issue to promote right person in right place to develop herbal medicine to the upcoming world.
\end{abstract}

Keywords: Herbal medicine; Mobilization; Therapeutic system; WHO

\section{Introduction}

Herbal medicine becomes an emerging and reemerging medicine to the scientific era. To communicate with resource partners, mobilize, utilize the resources and develop the infrastructure are very important approaches to propagate the herbal medicine in the world. Resource mobilization for development of herbal medicine is a challenging exercise. By using proper men, materials and money within the proper time and proper place, herbal medicine will become a most acceptable and affordable therapeutic system to the upcoming world. Planning, implementation, monitoring and evaluation are included in the resource mobilization strategy. It has been observed that men who are expert in the herbal medicine are not placed in the right place. Other disciplinary personnel are playing vital role to ruin the herbal medicine, though he or she didn't have vast knowledge to generalize, to propagate or to develop the herbal medicine. It is needed to carry the proper men in proper place; technological adaptation and country specific financial stability for development of herbal medicine. A corrective, promotive and science based policy needs to be initiated for HM. Setting up of a permanent council or commission on herbal medicines (HM), issuing policy statement, recognizing the historical role of complementary and traditional medicines in providing health care, mobilization of resources for the development of HM, training of health workers at the community level for using HM to treat common diseases and establishment of institutions which deals with necessary measures to protect intellectual property and include efforts to link with internationally accepted integrated system with mainstream health care system [1]. It is necessary to recognize, respect and endorse by governments for full actualization of their potential. The WHO has stated that Traditional, Complementary and Alternative Medicine are officially recognized element of healthcare: the integrative system, the inclusive system and the tolerant system [1] (WHO, 2002) [2]. Integration is currently being practiced in China, the Koreas, and
Vietnam and supported by Australia [2] (Cohen, 2004). China, India, Canada, Nigeria, Mali and UK among others, provide governmental support to strengthen training, research and the use of HM in their national healthcare strategies. Similar practices are also observed in other parts of the world, including the European Union (EU) and the Americas. The Government of Bangladesh also has taken positive initiative to develop, to establish and to propagate herbal medicine from grass-root to top level [3].

\section{Historical background for development of herbal medicine [3]}

Nobody knows when humans began to use herbs for medicinal purposes. The first written record of herbal medicine was found in China in 2800 B.C.

2800 B.C. - The first written record of herbal medicine was found as "the Pen Ts'ao" by Shen Nung.

400 B.C.- Hippocrates described the ideas of diet, exercise and therapeutic efficacy of herbs for wellbeing.

50 A.D.- The Roman Empire were tried to spread herbal medicine and given emphasis for cultivation of herbs.

200 A.D.- Galen was also classified common illnesses with their therapeutic values of herbs.

800 A.D.- Monks took over the herbs with herbal gardens at most monasteries and applied herbs for the health ailments.

1100 A.D.- Avicenna wrote the Canon of Medicine and described the details of herbal medicine.

1200 A.D.- Europe and other countries were used herbal medicine alongside "modern" methods such as bleeding, purging, arsenic and mercury for better results.

1500 A.D.- Herbal medicine and herbalists were promoted and supported by Henry VII. 
1600 A.D.- It was assumed that herbs were used for treating the poor communities, while extracts of plant, minerals, and animals (the "drugs"), were used for the rich communities.

1700 A.D.- Herbal medicine got another high profile endorsement from Preacher Charles Wesley. He advocated for sensible eating, good hygiene and herbal treatments for healthy living.

1800 A.D.- Pharmaceuticals began to formulate herbal drugs and documented the formulations.

1900 A.D.-Lack of availability of drugs during World War-1 increased the use of herbal medicines again. After that pharmaceutical production increased and penicillin was discovered. Herbal practitioners had their rights to dispense their medications taken away and then reinstated. The British Herbal Medicine Association was founded and produced the British Herbal Pharmacopoeia.

2000 A.D.-EU took action on regulation and testing of herbal medicines similar to those used for pharmaceuticals.

Historical evidence showed that from ancient to till now herbal medicine has been empirically used for treatment of different health ailments. Scientist, herbalist, physicians and experts from diversified fields are contributing to develop herbal medicine in the world. All of the researchers are morally coincided that maximum utilization and mobilization of resources (men, materials and money) are prime demand to propagate herbal medicine in the world. Some of the scientist also claimed that lack of expert in the field of herbal medicine is prime drawback to develop herbal medicine. It is true but expert in the field of herbal medicine are until struggling for positional crisis. Without changing the propaganda, it is not possible to achieve the desire goal of herbal medicine. So, it is time demanded issue to promote right person in right place to develop herbal medicine to the upcoming world.

\section{Strategic Differentiation of Resource Mobilization}

As we know, the resource mobilization composed of multiple elements like strategic position, review the resource requirement, analyze the external resource environment, establish the goal and expected outcomes of the RM, identify the potential resource partners and match with priority and develop an action plan [3,4]. It is not possible to change the all strategies within short time. A comprehensive approach is required to change the pattern of resource mobilization. Element specific analysis is required to concise the decision of resource mobilization.

First important elements of analysis are strategic position and review the resource requirement. It is needed to evaluate which and why the position is required to mobilize and what will be expected outcome of the mobilization. As a management principle, team leader of an effluent industry has to be honest, dynamic, highest rank achiever, excellent academic background, motivated and vast knowledge and experiences in the field of the industry. He/she can lead the industry and work efficiently and smoothly without any hastening. So, it is needed to mobilize the eminent personnel in the international (WHO -Herbal Medicine Wing) [3-5], national (Director-DGHS), primary (MO/THO), secondary (Civil Surgeon/DHO) and tertiary (Head of the Medical College and Hospital) level to develop the herbal medicine or according to country specific natural resource management policy [5]. It is proved that expert in the specific field can change the scenario of that field within short time frame.
Another important element is analyzing the external resources. To establish a sustainable system, it is needed to search the expert in that field, associated field and enriched by diversified field of experts. To form an international expert panel, it is mandatory to search the field of expertise in the developed, developing and middle income countries and their contributions, qualities, expertise and etc. After that, from the applicants, it is required to verify their information's, interviewed by expertise and others assessing tools to select the leader for the international committee. He/she will lead the system for 2-3 years. For that purpose, help can be seeking from eminent personnel's or institute (National Institute of Unani Medicine, India; National Institute of Ayurvedic Medicine; India; Aligarh Muslim University, Jamia Hamdard, Delhi and Pakistan, Hamdard University Bangladesh, Government Unani and Ayurvedic Medical College, Dhaka, Scottish School of Herbal Medicine, Milagro School of Herbal Medicine, Helen Begadon - Irish School of Herbal Medicine, Farida Sharan - School of Natural Medicine International, California School of Herbal Studies; North American Institute of Medical Herbalism and The National Institute of Ayurvedic Medicine, New York, USA etc.) for leader of the international committee. The leader of the international committee will select the other team member with the help of expert panel from the different countries and set up immediate, intermediate goal and long term goal and prepare an action plan to develop the herbal medicine in the scientific world.

\section{Prospective Strategies of RM for Development of Herbal Medicine}

Positional displacement is the major obstacle to set up RM strategies. Nobody can enthusiastically change his/her position. It is needed to motivate, to council for movement or replace to supportive agencies.

Financial crisis is also another great problem to set up a goal and object and achieve the goal of the system. So international funding agencies can be involved to develop the RM strategies of HM.

To search the proper men and the mobilize in the proper place are difficult task. For this purpose, government, non-government, national and international commitment is required to develop the herbal medicine in the world.

To establish the more and more Institutes, universities and medical college and hospital and research centers for propagate and development of herbal medicine.

Identify and communicate with interested resource partners and potential beneficiaries.

To prepare guideline for appropriate use of herbal medicines developed by the working groups which can be utilized fully or partially by member states depending on each country's own situation and distinct needs.

Establish the goal and intended outcomes of the RM strategy as well as guiding principles for resource partner's engagement.

Randomized Clinical trials/comparative CT/multi centre studies are required to develop HM in the world.

\section{Conclusion}

It is very difficult task to change something or introduce something to the existing system. A lot of obstacles or problems are enrolling for 
Citation: Mohammad NI (2017) Importance of Resource Mobilization (RM) for Development of Herbal Medicine: A Comprehensive Approach. J Bioengineer \& Biomedical Sci 7: 229. doi:10.4172/2155-9538.1000229

Page 3 of 3

minor shifting and drifting of the system. But for achievement of highest target, it is needed to form or reset or mobilize the resources.

\section{References}

1. Shahzad H, Farnaz M (2013) Integration of complementary and traditional medicines in public health care systems: Challenges and methodology. J Med Plants Res 7: 2952-2959.
2. WHO (2002) Traditional Medicine Strategy 2002-2005.

3. Thordur S (2016) History of herbal medicine. The herbal resources.

4. Okigbo RN, Mmeka EC (2006) An appraisal of phytomedicine in Africa. KMITL Sci Tech J 6.

5. Anita S, Simone L (1957) Field study on indigenous knowledge on natural resources in Samburu County Kenya. 